\title{
Oxidation resistance of plasma coated and laser treated mild steel
}

\author{
A.S. Khanna $\left({ }^{1}\right)$, R.K. Singh $\operatorname{Raman}\left({ }^{2}\right)$ and E.W. Kreutz $\left({ }^{3}\right)$ \\ ( $\left.{ }^{1}\right)$ Corrosion Science \& Engineering Department, Indian Institute of Technology, Bombay - \\ 400 076, India \\ $\left(^{2}\right)$ Indira Gandhi Centre for Atomic Research, Kalpakkam, India \\ $\left({ }^{3}\right)$ Fraunhofer Institute for Lasertechnik, Aachen, Germany
}

\begin{abstract}
Stainless steel powder was coated on mild steel substrate using plasma coating. The porous coating thus obtained was modified using laser irradiation. The oxidation behaviour of the plasma coated as well as laser treated material was studied in air at $1073 \mathrm{~K}$. There was considerable decrease in oxidation rate of mild steel after plasma coating as expected. In addition the oxidation resistance improved significantly after laser treatment. Various laser parameters influence the coating characteristics. Their effect on coating composition and on oxidation rate is discussed.
\end{abstract}

\section{Introduction.}

Surface alloying using laser irradiation has emerged as an important technique for improving oxidation, corrosion and wear of metals and alloys [1-4]. The process consists of modifying the surface of relatively inexpensive substrates by adding small quantities of alloying elements to a pool of molten metal produced by local melting using an intense, focused laser beam. The main advantage are the ability to melt any metal and the formation of novel microstructure due to very high cooling rates involved.

Plasma coating is a well known technique for the formation overlay coatings on many less noble substrates [5]. However, there are a few limitations of this technique: formation of highly porous coated layers, rough coating surface and weak physical bonding with the substrate [6]. Some improvements, however, can be achieved by heat treatment at high temperatures. Alternative way is to irradiate with laser beam, which not only increases the density of coating layer but also improves the microstructure due to rapid cooling involved [7].

In the present work, effect of various laser parameters has been studied on the characteristics of plasma coated stainless steel layer and also the effect of such coated layers on their oxidation behaviour.

\section{Experimental.}

Mild Steel plates $(100 \times 50 \times 3 \mathrm{~mm})$ were plasma coated using plasma torch method at TAFA Incorporated, U.S.A.. A $100 \mu \mathrm{m}$ stainless steel layer thus deposited was laser treated using a continuous wave carbon dioxide laser. Laser parameters chosen are given in table I. These parameters varied the interaction time from 8 to $64 \mu \mathrm{s}$, depending upon the sweep rate of 2000 to $250 \mathrm{~mm} / \mathrm{min}$ respectively. Laser power was kept constant at $3 \mathrm{~kW}$. The treatment was 
carried out in the presence of argon (flow rate $301 / \mathrm{min}$ ) as shielding gas. Eight different sets of samples were obtained depending upon their interaction time and laser sweep rate. Their designation with sweep rate and depth of thickness achieved are given in table I. Coating characterization was carried out using optical microscopy and electron probe microanalysis.

Table I. - Thickness of laser melted zone at various laser sweep rate.

\begin{tabular}{|c|c|c|}
\hline $\begin{array}{c}\text { Designation of } \\
\text { laser treatment }\end{array}$ & $\begin{array}{c}\text { Laser sweep rate } \\
\mathrm{mm} / \mathrm{min}\end{array}$ & $\begin{array}{c}\text { Thickness } \\
\mu \mathrm{m}\end{array}$ \\
\hline LT1 & 2000 & 143 \\
LT2 & 1750 & 149 \\
LT3 & 1500 & 156 \\
LT4 & 1250 & 185 \\
LT5 & 1000 & 234 \\
LT6 & 750 & 294 \\
LT7 & 500 & 370 \\
LT8 & 250 & Whole cross section \\
\hline
\end{tabular}

Oxidation tests were carried out by exposing to air ( 1 atm pressure) using $1 \mathrm{~cm}^{2}$ specimen at $1073 \mathrm{~K}$ for a duration of $6 \mathrm{~h}$ in a Mettler TAl thermogravimetric balance. In addition, oxidation tests were carried out under thermal cycling conditions by exposing the specimens to 12 cycles from 1073 to $573 \mathrm{~K}$. In each cycle, the specimen was first heated to $1073 \mathrm{~K}$ and maintained at this temperature for $1 \mathrm{~h}$ followed by cooling to $573 \mathrm{~K}$ with an hold time of $30 \mathrm{~min}$. This test was to estimate the integrity of the scale in terms of its spallation resistance and adherence to the substrate.

\section{Results.}

3.1 Characterization Of LASER treated SAmples. - Figure I shows the cross-section of the plasma coated sample taken using optical microscope after light etching with nital solution. The total scale thickness was found to be of $100 \mu \mathrm{m}$ and it appears very porous and has uneven surface. Some grain growth is also seen next to the coating/metal interface. After laser treatment, the thickness of the melting zone varied depending upon the laser parameters. The thicknesses achieved by varying the laser sweep rate are given in table $\mathbf{I}$. It is apparent from this that at lower sweep rate, when the interaction time is more important, there is sufficient dilution of alloying components from coating while at faster sweep rate the dilution is limited because of lower interaction time. Further, it is clear that there is a little difference in the thickness of melted zone when the laser sweep rate varies from 2000 to $1200 \mathrm{~mm} / \mathrm{min}$. Beyond this the melted zone involves large thickness.

Electron probe microanalysis was used to check the changes in composition of the alloying elements in the coating and their diffusion in the matrix. These results are shown in figure 2 in terms of the concentration of $\mathrm{Fe}, \mathrm{Cr}$ and $\mathrm{Ni}$ in the plasma coated and various laser treated specimens. Figure $2 \mathrm{a}$ compares the $\mathrm{Cr}$ profile in plasma coated and laser treated specimens, 


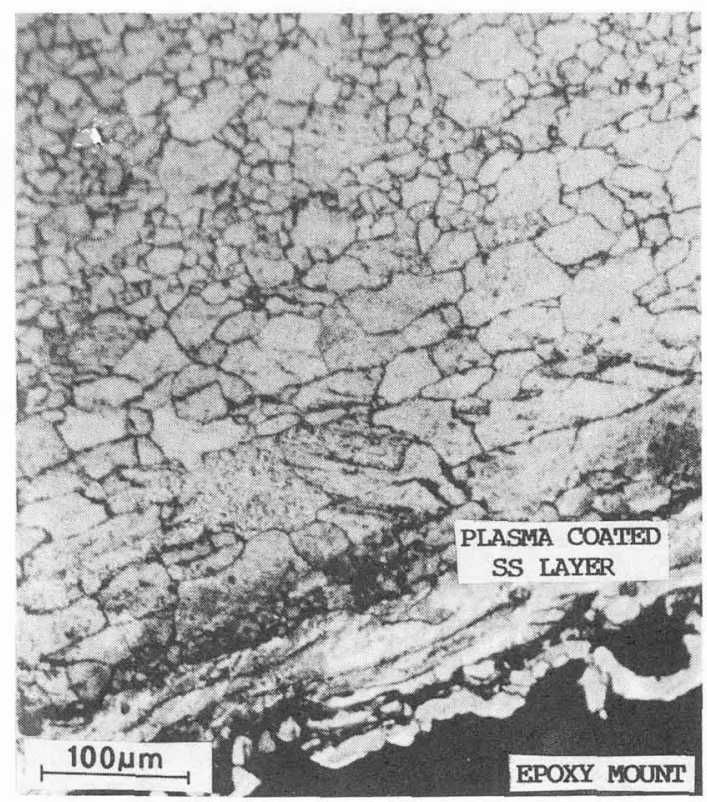

Fig. 1. - Optical micrograph showing plasma coated stainless steel layer on mild steel.

indicating the increase in the thickness of dilution layer with increase in the interaction time. The Cr concentration in the plasma coated samples is about $18 \mathrm{wt} \%$ (the normal concentration in 18/8 austenitic stainless steel). Throughout the plasma coated layer, the thickness remains around $18 \% \mathrm{Cr}$ after which the concentration falls to zero as mild steel does not contain any Cr. In the laser treated specimens, the Cr concentration in the coated layer falls below 5 wt $\%$ and the thickness of the melt zone in the matrix containing $\mathrm{Cr}$ increases, leading to dilution of the original layer. Laser parameters with low interaction time such as in LT5, result in lower thickness of diluted zone compared to those having longer interaction time such as in specimen LT8. In fact, in LT8, presence of $\mathrm{Cr}$ can be seen throughout the matrix. The same is true for $\mathrm{Fe}$ and $\mathrm{Ni}$ shown in figures $2 \mathrm{~b}$ and $2 \mathrm{c}$ respectively. Thus EPMA results are, in close conformation to the optical microscopic results, which for example show no clear demarcation between laser melted zone in LT8, indicating dilution of alloying components throughout the substrate thickness.

3.2 OXIDATION KINETICS. - Oxidation tests at $1073 \mathrm{~K}$, carried out in air, showed in general parabolic kinetics (Figs. 3 and 4). Oxidation resistance of the mild steel samples is enhanced after plasma coating. Laser treatment helps in reducing the oxidation rate still further. To explain the effect of laser treatment on the oxidation behaviour, various treatments are divided into two categories: those where coating alone is improved (for example in the case of LT1 to LT5) (i). Because of low interaction time, very little dilution of the coating has taken place and hence the stainless steel coating is able to protect the mild steel substrate. Further, it is interesting to note that oxidation kinetics of all the four samples LT1-LT5 fall under one kinetic plot, indicating very little difference in the oxidation behaviour of these samples. However, when the oxidation kinetics of these samples is compared with that of other samples especially LT7 and LT8 (Fig. 4), the oxidation rate increased significantly. Such samples fall 

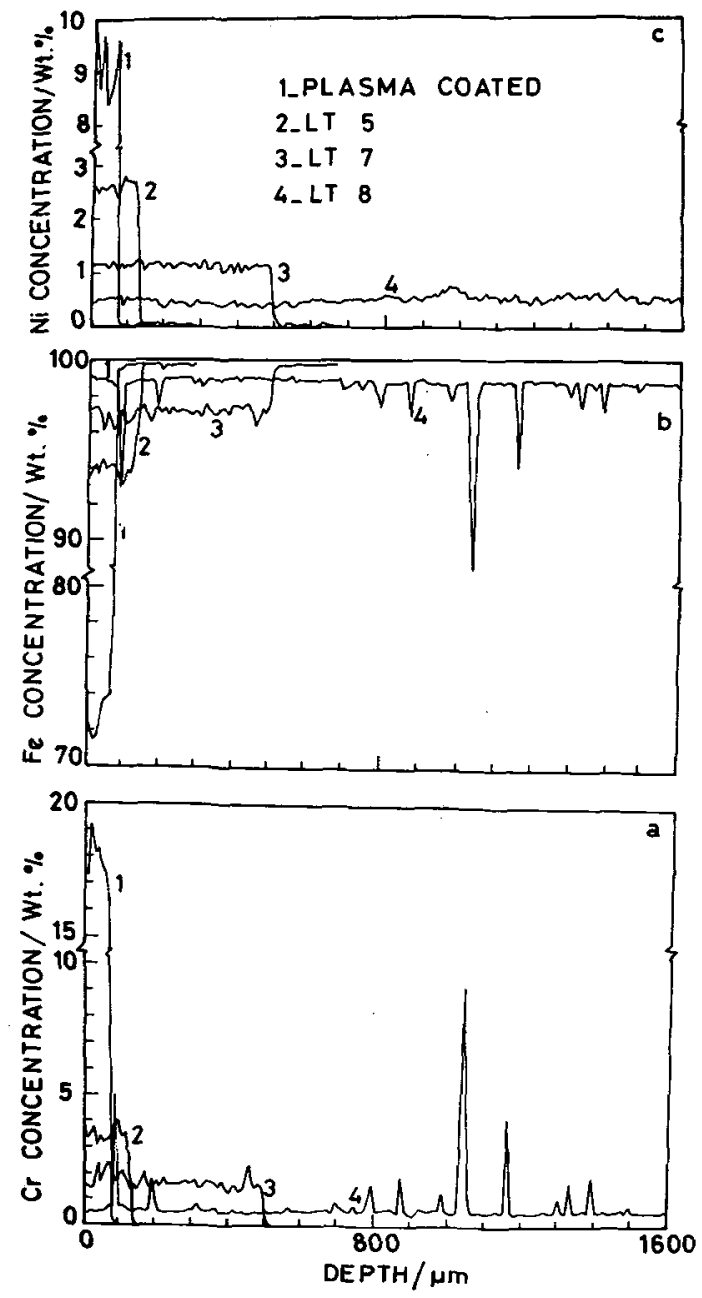

Fig. 2. - Concentration profiles, measured using EMPA on plasma coated and laser treated specimens (LT5, LT7 and LT8): a) ( $\gamma$; b) Fe and c) Ni.

in second category, where because of larger interaction time, most of the important alloying elements have been diffused into the matrix. Lowest oxidation resistance among the laser treated specimens is for LT8 where maximum dilution has taken place.

The oxidation resistance was found to be influenced strongly when the laser treated surface was oxidized after polishing. Polishing was carried out by grinding the laser treated surface on a $600 \mathrm{Grit} \mathrm{SiC}$ paper until the dull gray coating was removed giving a shining substrate surface. Specimens of category (i), described above show considerable increase in oxidation rate while those falling in category (ii) did not show much change in oxidation rate (Fig. 5). This is obvious that in category (i), since all the alloying constituents are concentrated, polishing would remove these important alloying elements resulting in increasing the oxidation rate. Specimens in second category represent those where extensive dilution has taken place from the surface, therefore additional polishing would not affect the oxidation rate significantly. 


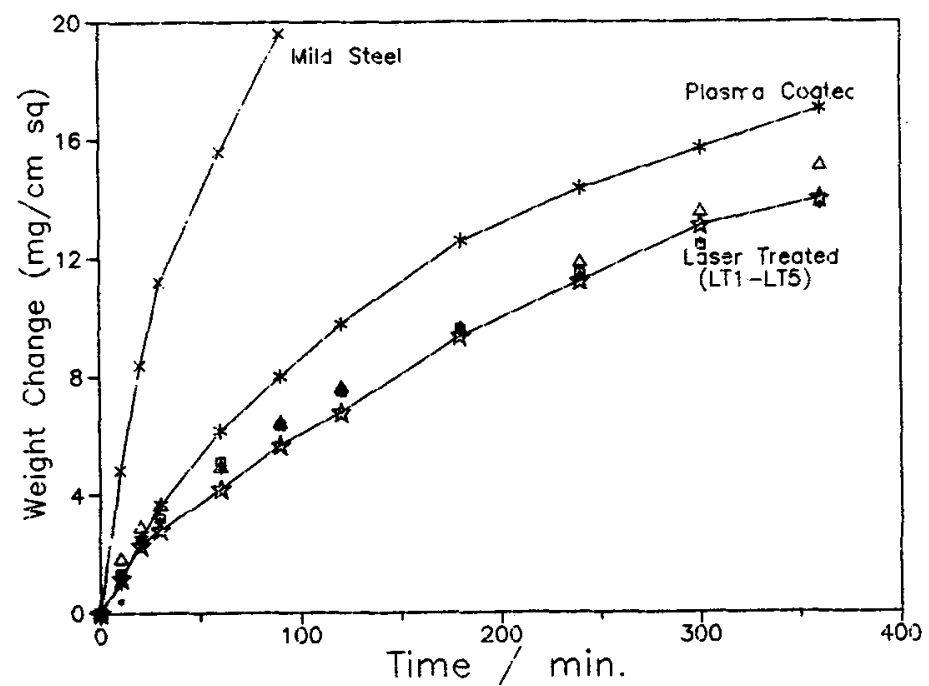

Fig. 3. - Weight gain vs. time plots for the oxidation of mild steel, plasma treated and laser treated steel at $1073 \mathrm{~K}$ in air.

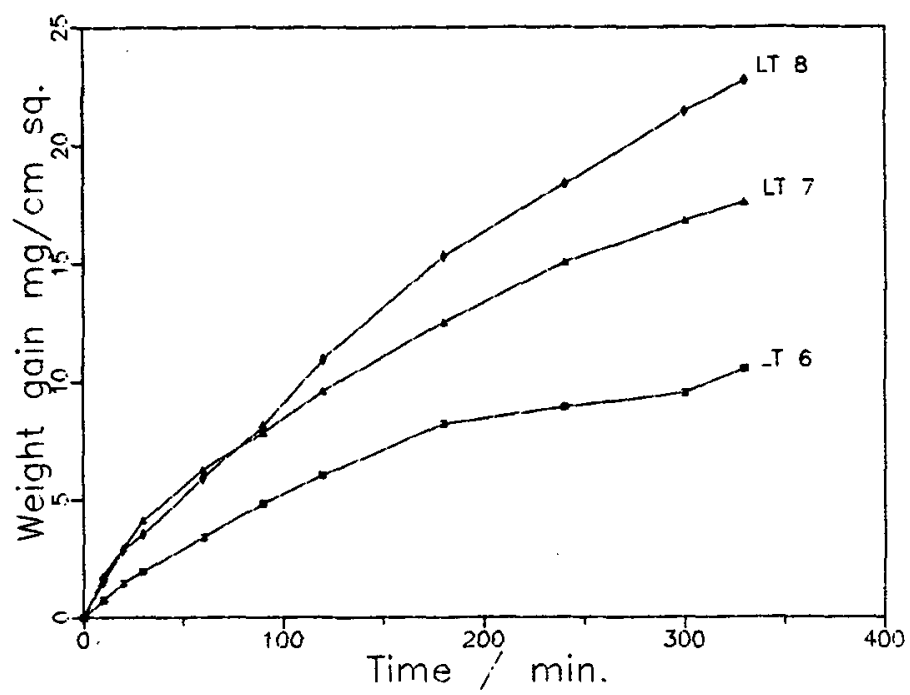

Fig. 4. - Weight gain vs. time plots for the oxidation of laser treated steel at $1073 \mathrm{~K}$ in air.

A little difference was noted in the thermal cycling behaviour of the plasma coated samples and the one treated with laser also. Lower weight gain during oxidation in 12 cycles indicates that the adherence might have improved slightly followed by laser treatment (Fig. 6). 


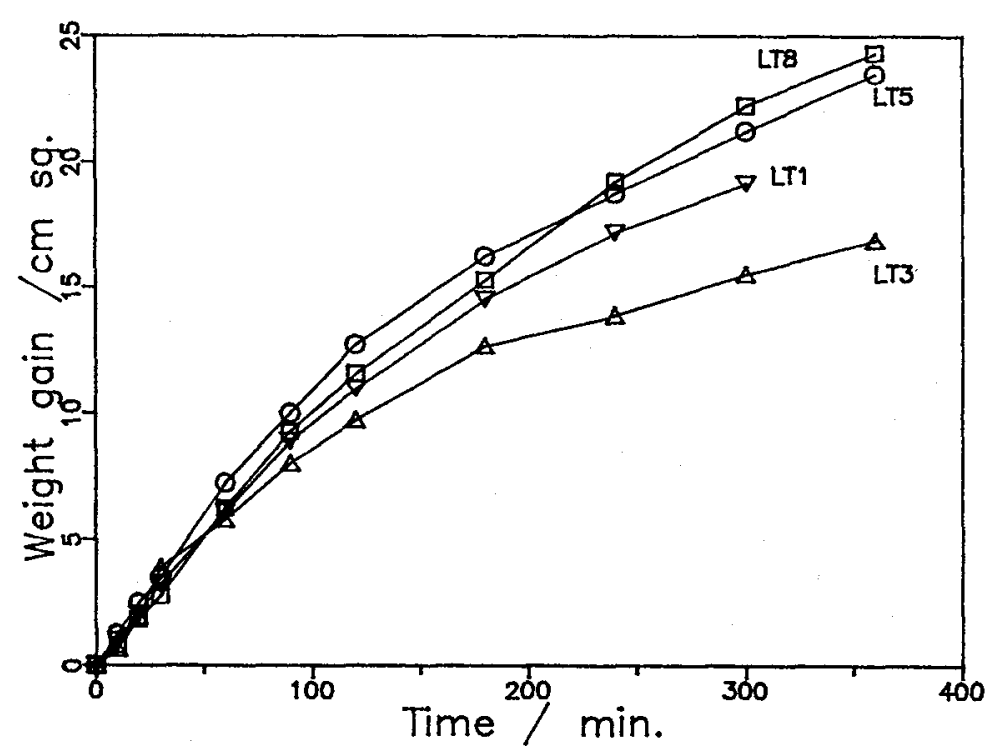

Fig. 5. - Weight gain vs. time plots, showing the effect of polishing on the oxidation of laser treated steel at $1073 \mathrm{~K}$ in air.

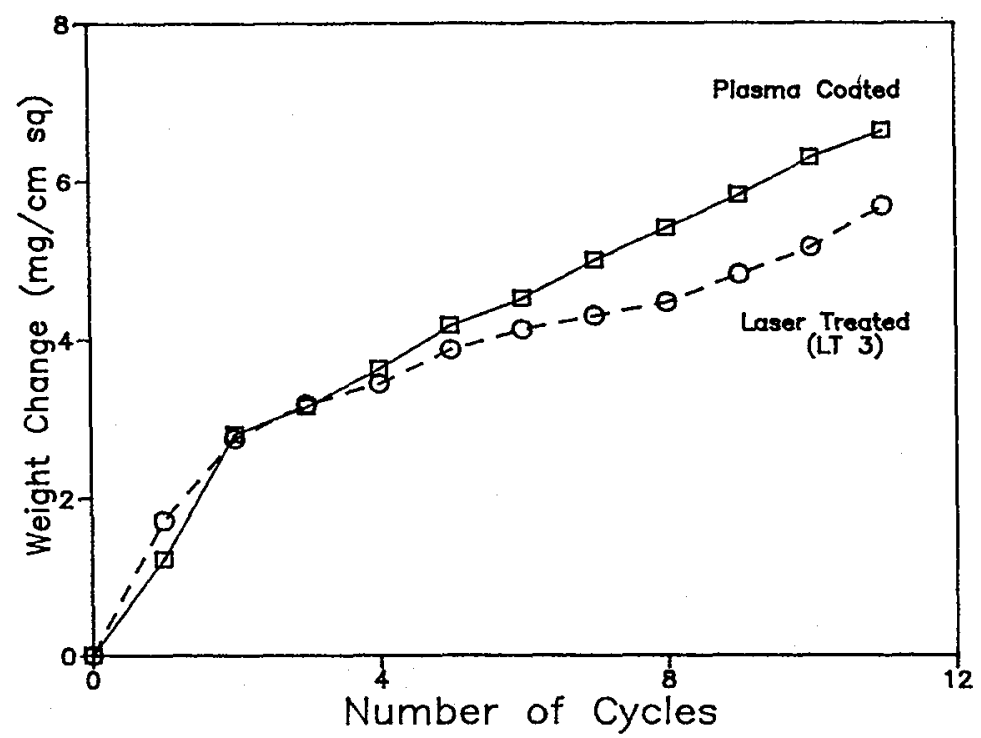

Fig. 6. - Weight gain vs. time plots for the oxidation of plasma treated and laser treated steel under thermal cycling conditions between $1073 \mathrm{~K}$ to $573 \mathrm{~K}$ in air.

\section{Discussion.}

Laser treatment significantly improved the plasma coated layer by making it more dense and smooth. Interaction time seems to be a very important parameter to decide the final proper- 
ties of the coating. Large interaction time results in considerable dilution of alloying elements in the coating and therefore reduces its effectiveness to protect the base metal. If the main aim is to protect the base metal then a lower interaction time is preferred for laser treatment; however, laser parameters involving large interaction times are required for forming surface alloys.

Plasma coating of $18 / 8$ stainless steel has considerably reduced the oxidation rate of mild steel. The oxidation rate of the coated materials is, however, not same as that of $18 / 8$ stainless steel. The reason may be very rough and the porous coating surface. Also small samples which were cut from coated surface had uncoated mild steel edges whose oxidation has not been properly taken care in measured oxidation rate. Laser treatment has significantly reduced the oxidation rate and this improvement can be attributed to the increased surface smoothens and reduced porosity and also due to better substrate to coating bond. Oxidation of the sample treated with large interaction time (specimen LT8), although, shows higher oxidation rate than that of other laser treated samples and plasma coated samples; nevertheless it has still lower oxidation rate than the mild steel. This is because of bulk alloying of this sample in terms of $\mathrm{Cr}$ and $\mathrm{Ni}$ which provided additional protection. This was confirmed from the chromium rich scale formed upon oxidation of this sample compared to an iron oxide on mild steel sample. Mechanical polishing of this sample did not affect the oxidation rate as the alloying constituents were distributed across the scale rather than at the coating. While in other cases where significant dilution of the alloying elements has not taken place, mechanical polishing resulted in removing the important alloying constituents and therefore, resulting in poor oxidation behaviour.

\section{Conclusions.}

Laser treatment of stainless steel powders, plasma coated on mild steel resulted in a dense, smooth and strongly bonded layer to the substrate. Treatment with large interaction time resulted in considerable dilution of the alloying constituents of the coating and hence were less effective in protecting the mild steel substrate from oxidation. Low interaction treatment was beneficial in providing enhance corrosion resistance to mild steel.

\section{Acknowledgements.}

The authors are grateful to Mr. Adolfo Castells, sales manager, TAFA Incorporate U.S.A., for providing the plasma coated samples. They gratefully acknowledge the help rendered by Dr. A. Gasser and K. Wissenbach of Fraunhofer Institute for Lasertechnik, Aachen for helping in laser irradiation and Mr. A.L.E. Terrance of IGCAR, Kalpakkam for carrying out EMPA analysis.

\section{References}

[1] STtot F.H., Bartlett P.K.N., Wood G.G., Mater. Sci. Eng. 88 (1987) 163.

[2] Smeggil J.G., Funkenbusch A.W., Bornstein N.S., Thin Solid Films 119 (1984) 327. 
[3] Khanna A.S., Quadakkers W.J., SChuster H., GaSSer A., Wissenbach K., KreuTZ E.W., Structure and Reactivity of Surfaces, C. Morterra, A. Zecchena and G. Costa Eds. (Elsevier Publication, Amsterdam, 1989) p.535.

[4] Galerie A., Caillet M., Pons M., Proc. 10th Int. Congress on Corrosion (India, Nov. 1987) p.3671.

[5] GAPP M.L., RigSBEE J.M., Mater. Sci. Eng. 62 (1984) 49.

[6] RIgSBEe J.M., J. Met. 36 (1984) 31.

[7] MOORE P.G., Proc. Int. Symp. on Fundamental aspects of Corrosion protection by Surface Modifications, E. McCafferty, C.R. Clayton, J. Oudar Eds. (The Electrochemical Society of Inc., 1984) p. 102. 